\section{Social anxiety in patients with facial disfigurement}

Newell \& Marks (2000) highlight an important, under-researched area. They suggest treatment using cognitive-behavioural therapy, concentrating on exposure to avoided situations. However, their conclusions and recommendations appear broader than the data support.

They recruited from dermatology clinics, ex-surgery lists and media adverts. Their sample might therefore be expected to include subjects with less severe disfigurement or even a primary diagnosis of dysmorphophobia. The preponderance of women requires explanation when many conditions causing facial disfigurement affect both genders equally. The nature and severity of disfigurement should be described. Facial disfigurement can result from bone deformity, scarring, muscular paralysis or abnormal movement. It may be congenital or acquired and onset can be sudden or gradual at any age. Aetiology includes trauma, surgery, neoplasms and infections and likelihood of recovery varies greatly. All these factors are likely to influence the psychological difficulties experienced, including those manifest in social settings. Exposure would only be expected to help the phobic components of these problems.

Impaired control of functions important in social situations - including eating, drinking, speaking and facial expression and altered self-image and differences in the reactions of others are likely to require changes to the routine advice given to people with social phobia. Repeated exposure to distressing events such as dribbling may reinforce negative thoughts about the self rather than minimise anxiety, as in typical phobic states. Specialist advice regarding make-up has improved patients' confidence and mood (Kanzaki et al, 1998), which would be expected to aid social interaction despite helping patients 'avoid' their true appearance.

Newell \& Marks' study, therefore, does not support the conclusion that all social anxiety in patients with all types of facial disfigurement has the same psychopathology as social phobia. Cognitive-behavioural interventions probably need to address more than the avoidance or beliefs typical of social phobia. The need for exposure, a range of cognitive techniques, grief work, specialist physiotherapy and speech therapy is likely to vary. Future research should describe the type, course and severity of disfigurement and associated difficulties and clarify specific concerns occurring in social settings.

Kanzaki, K., Ohshiro, K. \& Abe, T. (1998) Effect of corrective make-up training on patients with facial nerve paralysis. Ear, Nose, and Throat Journal, 77, 270-274.

Newell, R. \& Marks, I. (2000) Phobic nature of social difficulty in facially disfigured people. British Journal of Psychiatry, 176, 177-181.

J. A. Butler Mental Health Group, University of Southampton, Royal South Hants Hospital, Brintons Terrace, Southampton SOI4 OYG

Authors' reply: We welcome Dr Butler's comments and endorse the call for further research in the area of psychological difficulties following disfigurement. While we accept the call for caution, given the heterogeneous nature of our sample, we believe our conclusions are appropriately modest. We do not suggest either that phobic avoidance is the sole element of psychological distress following disfigurement, or that "all social anxiety" in such people has the "same psychopathology as social phobia". Indeed, the role of multiple contributing factors to such distress has been emphasised by one of us (Newell, 1991), and we noted our awareness of, but inability to investigate, the role of stigma. Moreover, Newell (1991) stresses the importance of sensitivity when advising of exposure exercises, precisely to reduce the potential for reinforcing negative thoughts and increasing anxiety, as Dr Butler suggests. More generally, the need for individualised treatment has been repeatedly stressed in behaviour therapy and cognitive therapy, although self-help methods (which, of necessity, give general prescriptions of advice which clients modify themselves) show promise. In the context of disfigurement, a simple self-help leaflet (Newell \& Clarke, 2000) produced modest benefits relative to untreated controls and of a level roughly similar to those found in a group social skills intervention (Robinson et al, 1996).

Although the nature of the sample is important, it is difficult to obtain participants from this group, as previous studies have found. However, findings regarding gender differences among disfigured people with respect to psychological disturbances have been equivocal, and findings tend to suggest that level of disfigurement is a poor predictor of psychological adjustment.

Exposure therapy is obviously not a panacea, but rather a promising approach to psychological disturbance following disfigurement where social anxiety is present.
Dr Butler rightly draws attention to the need for flexible, individually tailored treatment, although this is questioned by some results (Schulte et al, 1992). There is likewise a need to avoid the inclusion of poorly supported interventions, and to build an appropriate evidence base. For example, we know of no studies that demonstrate the effectiveness of grief work among people with disfigurement, and there is likewise little evidence of the effectiveness of other interventions for psychological difficulties following disfigurement, despite the size of the problem.

Newell, R. J. (1991) Body image disturbance: cognitivebehavioural formulation and intervention. Journal of Advanced Nursing, 16, 1400-1405.

_ \& Clarke, M. (2000) Evaluation of a self-help leaflet in treatment of social difficulties following facial disfigurement. International Journal of Nursing Studies, in press.

Robinson, E., Rumsey, N. \& Partridge, J. (1996) An evaluation of the impact of social interaction skills training for facially disfigured people. British Journal of Plastic Surgery, 49, 28I-289.

Schulte, D., Kunzel, R., Pepping, G., et al (1992) Tailormade versus standardized therapy of phobic patients. Advances in Behaviour Research and Therapy, 14, 67-92.

R. Newell School of Healthcare Studies, University of Leeds, 22 Hyde Terrace, Leeds LS2 9LN

I. Marks Maudsley Hospital, De Crespigny Park, Denmark Hill, London SE5 8AZ

\section{Outcome of hospital-treated depression}

" 'Then you should say what you mean', the March Hare went on. 'I do,' Alice hastily replied; 'at least - I mean what I say-that's the same thing, you know.' " (Lewis Carroll, Alice in Wonderland).

Tuma (2000) gives a 'recovery' rate of $24 \%$ for depressed elderly patients but this figure actually refers to his category 'lasting recovery'. If the term recovery may be used to include those who have relapsed but then recovered for a (specified) period of time, the rate from Tuma's study is $44 \%$, or $66 \%$ once natural deaths have been removed. Tuma appears to be following Murphy's (1987) view of recovery in depression as being a pint-pot only half-full.

This is not to disagree with the conclusion drawn from the study's data that elderly patients with depression have a poorer prognosis than younger adults, but there is a need to respond to the call for more clarity, if not unanimity, in what terms mean (Frank et al, 1991). Low detection and treatment rates for depression in 